\title{
Reply to comment on Irena Krusche-Mandl et al. crossed pinning in paediatric supracondylar humerus fractures: a retrospective cohort analysis
}

\author{
Irena Krusche-Mandl • Silke Aldrian • \\ Julia Köttstorfer • Astrid Seis • Gerhild Thalhammer • \\ Alexander Egkher
}

Received: 8 January 2013 / Accepted: 8 January 2013 /Published online: 29 January 2013

(C) Springer-Verlag Berlin Heidelberg 2013

\section{Dear Editor,}

Regarding the comments to our article published in International Orthopedics [1], the authors have chosen to use the visual analogue scale (VAS) (0-10), because in their opinion children aged five years do not really know or can properly judge the difference between " 42 " and " 47 "; they can handle a " 4 " or " 5 " much better. The authors did discuss this point with their clinical psychologist and she agreed on that. Certainly, at follow-up the patients were older and a score between 0 and 100 would be mathematically more precise. Since none of the patients reported any relevant pain symptoms, only $1 / 78$ had a $1 / 10 \mathrm{VAS}$, thus resulting in an average of 0.012820513 ; the authors rounded this figure and specified the range $(0-1)$. The authors agree that this figure is more accurate, but in this particular case, they do not see a benefit to the readership in discussing this in detail.

\section{Reference}

1. Krusche-Mandl I, Aldrian S, Köttstorfer J, Seis A, Thalhammer G, Egkher A (2012) Crossed pinning in paediatric supracondylar humerus fractures: a retrospective cohort analysis. Int Orthop 36 (9):1893-8

I. Krusche-Mandl $(\bowtie) \cdot S$. Aldrian · J. Köttstorfer $\cdot$ A. Seis $\cdot$

G. Thalhammer $\cdot$ A. Egkher

Department of Trauma Surgery, Medical University of Vienna,

Währinger Gürtel 18-20,

1090, Vienna, Austria

e-mail: irena.mandl@gmx.at 